\title{
A simulation model to measure the impact of introducing new procedures in cardiology
}

\author{
M H Wilke*, R Grube \\ From 26th Patient Classification Systems International (PCSI) Working Conference \\ Munich, Germany. 15-18 September 2010
}

\section{Introduction}

Percutaneous coronary interventions (PCI), like angioplasty or stents, are well established and reflected in DRG payment. However, recent scientific evidence shows that a significant number of patients having socalled intermediate stenoses (i.e., a stenosis diameter bt. $40 \%-70 \%$ of the total coronary calibre) do not necessarily profit from PCI.

A diagnostic test - the measurement of the coronary flow reserve (FFR) is available. The FAME study (Fractional Flow Reserve versus Angiography for Guiding Percutaneous Coronary Intervention, Tonino et.al., N Engl J Med 2009;360:213-24) showed that refusing PCI in an intermediate stenosis where the FFR is $>0.8$ results in better outcomes than performing PCI. There is strong evidence for using FFR before performing a PCI in an intermediate stenosis.

On the other hand, FFR itself causes costs (approximately $€ 900$ ). The procedure code for FFR is already incorporated in the German DRG system, Version 2010.

The research questions in this setting were:

1) What would happen if cardiologists in a hospital introduced FFR, as recommended in the FAME study?

2) How would the number of PCIs change?

3) What effect would occur on the total reimbursement in the cardiac catheterization laboratory?

\section{Materials and methods}

In order to answer the research questions posed above, a proprietary computer-based simulation model was designed. Based on a database containing approximately 1 million patient records from approximately 100 hospitals for the year 2009, we retrospectively selected a

Dr. Wilke - inspiring.health, Munich, Germany population of 22,484 patients who had received an angiography, a percutaneous coronary intervention, or other cardiac catheterization procedures, and who had not had an acute myocardial infarction.

For this group, we calculated the proportion of patients eligible for FFR, applying the criteria used in the FAME study, and we compared this with the real documented FFR use in this group from our database. We then added the FFR code to all eligible patients and regrouped the population with the G-DRG Grouper 2010. In our simulation model, we also calculated the impact that FFR use would have in avoiding stenting; i.e., in moving from DRGs with stents to those without stents.

FFR should be limited to those cases of intermediate stenoses where the decision for or against PCI cannot be taken without further diagnostics. We obtained an estimate of the prevalence of intermediate stenoses in the German patient population through a survey of a number of hospitals. In addition, we took data from the literature (Coronary Pressure 2nd edition, by Nico Pijls, Bernard De Bruyne; Kluwer Academic Publishers 2000 - p. 27, fig. 3.1).

\section{Results}

As an intermediate result, we separated the DRGs by checking whether or not FFR causes changes in the DRG assignment. These results were used to participate in the annual structured dialogue process of the InEKinstitute in Germany, and resulted in the application for funding of FFR in one-day cases.

7,769 patients got a PCI (at least on lesion stented). After running these patients through the model, and based on the above assumptions of FFR eligibility, 4,506 of these patients should potentially undergo FFR. Based on the FAME results, this would mean that 2,478 patients would, as a result of FFR, have one stenosis less to be stented. This means that 882 patients still end up 
in a PCI-DRG, whereas 1,596 patients end up in a nonPCI (diagnostic) DRG.

From 14,715 patients having no PCI in the historical data, we excluded $75 \%$ having unsusceptible coronary angiography results. Thus 3,679 should undergo FFR in addition to the coronary angiography. From these again, 1,655 (based on FAME data) would have a hemodynamically relevant stenosis and undergo PCI, which would result in a different DRG. Running all cases through the model we saw DRG-changes in 8,185 patients.

Economical Impact of Introducing FFR in Hospitals

Before FFR (original data), the 22,484 patients had an average DRG price of $€ 2,490.33$. After running the simulation, we found an average DRG price of $€ 3,522.84$ in those patients that had undergone FFR and had further treatment (PCI, PCI of at least one lesion, or no further PCI).

Looking at the average cost of FFR - which is approximately $€ 1,000$ - we can conclude that FFR is well reflected in the G-DRG system 2010. Thus, clinicians in hospital can freely decide to use FFR according to the current guidelines without feeling that there is a substantial risk that the procedure will not be financed.

\section{Conclusions}

Looking at the results, we can answer the research questions as follows:

1) FFR seems to be covered in inpatient DRGs. However, the results can vary when FFR is applied on non-eligible patients, and the DRG distribution is different from our sample.

2) By using FFR, the number of unnecessary PCIs can be reduced by approximately $30 \%$, which enhances the quality of care for patients and saves money for insurers.

3) In one-day cases, FFR is not yet funded

Moreover, we found:

1) Simulating the financial impact of a clinically meaningful technology is feasible.

2) By using DRG routine data, and additional data from clinical studies, the simulation of changes in clinical behaviour can be done before investing in new technology.

Published: 6 October 2010

doi:10.1186/1472-6963-10-S2-A23

Cite this article as: Wilke and Grube: A simulation model to measure the impact of introducing new procedures in cardiology. BMC Health Services Research 2010 10(Suppl 2):A23.
Submit your next manuscript to BioMed Central and take full advantage of:

- Convenient online submission

- Thorough peer review

- No space constraints or color figure charges

- Immediate publication on acceptance

- Inclusion in PubMed, CAS, Scopus and Google Scholar

- Research which is freely available for redistribution

Submit your manuscript at www.biomedcentral.com/submit 